\title{
Critical Review of the Principles of Design for Disassembly
}

\author{
Ernest Kissi $^{1 *}$, Mark Ansah $^{2}$, Johnson Ampofo $^{3}$, and Emmanuel Boakye ${ }^{4}$ \\ ${ }^{1}$ Lecturer, Department of Construction Management and Technology, Kwame University of \\ Science and Technology, Kumasi-Ghana \\ ${ }^{2}$ PhD candidate, Department of Building Services Engineering, The Hong Kong Polytechnic \\ University \\ ${ }^{3}$ M.Sc. Candidate, Department of Construction Management and Technology, Kwame \\ University of Science and Technology, Kumasi-Ghana \\ *Corresponding author's e-mail: kisernest@gmail.com
}

\begin{abstract}
Design for disassembly (DfD) is a promising sustainable design paradigm for the construction sector development. Thus, the study provides a critical review on the principle of design for disassembly for a period of 8year. The study revealed that documentation of materials and methods, standardization of components and use mechanical joints instead of chemical joints were most frequent principle that are used for design for disassembly. The finding revealed that authors from Australia, United Kingdom and United states have made the most contribution to principles on DfD. Moreover, the study has provided a checklist to promote this design paradigm.
\end{abstract}

\section{KEYWORDS}

Principle; Design; Disassembly

\section{INTRODUCTION}

Construction demolition activities generates tremendous amount of debris. In the USA for instance, over $90 \%$ out of the 534 million tons of Construction and Demolition (C\&D) debris generated in 2014 was demolition waste (EPA, 2014). In China, construction waste accounts to about $40 \%$ of all municipal solid waste (Hao et al., 2011). Increase in waste generation alongside inefficiencies in reducing and effective management come with some levels of certain environmental and socioeconomic problems (Poon et al., 2003). A typical example is the expense of land fill construction and management. Construction waste is indeed ineluctable, however avoidable waste can be reduced significantly (Yuan et al., 2011). Lately, numerous researchers have made significant contributions towards this end, while some studies have focuses on recycling demolition waste, for instance, a project in Minnesota embarked on converting asphalt shingles from demolition waste to hot mix asphalt (Bosa and El-Gafy, 2011), others have also centred on reduction of waste right from design through construction to retiring buildings (Jaillon et al, 2017; Hossain et al., 2017; Ajayi et al., 2017).

In recent times, Design for disassemble (DfD) methodology is emerging, it is a concurrent solution to demolition through optimizing disassembly operations to allow for reuse. It offers a great potential to promote the circular economy. The are many applications of DfD within the 
construction industry with typical examples including prefabricated concrete elements, bolted steel and timber joints and bolted brick construction. Successful integration of DfD construction methods into the industry will require clearly articulated design guides or principles. There are indeed many studies on such principles over the past years. Despite the rise in interest DfD, little attention has been given to a review and analysis principle for design for disassembly already identified in literature. It is therefore valuable to critically review literature on principles for design for disassembly to provide insight into incorporating such measures into early stages of design. In this regard, the study critically reviewed scientific publication on principles of design for disassembly between the years of 2000 and 2018 inclusive.

\section{METHODS}

The study adopted a similar approached by Osei-Kyei (2015) and Darko and Chan (2017) by analyse academic publications within the years of 2000 and 2018. This enabled a methodological analysis of academic journals highly related in context to principles of design for disassembly. The first stage involved a search with academic journals then selection of target papers and finally analysing these papers. In pursuing the aim of the study, academic journals with publications on principles for design for disassembly were identified. A list of publication on design for disassembly was obtained using the search engine Scopus and google scholar. Scopus was chosen because it covers most publication databases (Hong and Chang, 2014). More specifically Scopus has been used in a number of similar literature review byDarko and Chan (2017), Osei-Kyei and Chan (2015), Hong and Chang (2014) and Yi and Wang, 2013. In addition, a substantial number of publication on DfD was also retrieved from Google Scholar and therefore added to the study.

This comprehensive search was carried out under the "title/abstract/keyword" field section of both search engines with these key words; "principles", "themes" and "guidelines" which are limited design for disassembly by using keywords "design for disassembly", "design for deconstruction" and "DfD". Initial search results include large amount of academic materials from mechanical and electrical manufacturing industry so the search was further limited to construction industry. Over two hundred and twelve articles were retrieved from the initial search. However not all articles identified were directly related to principles for design for disassembly. Some article happened to have just keywords from the search in their title or abstract section. It was therefore important to review these papers. The second stage therefore involved reviewing the articles to filter out those without content on the subject matter. After a brief review of the abstracts, sixteen papers were found relevant and therefore used for further analysis. The results of the study are solely based on the sampling procedure adopted and not a complete representation literature on principles for design for disassembly. These papers were reviewed for yearly publications, authors' origin and contribution, and findings on principles for disassembly. To determine the authors' contribution, the study adopted a formula proposed by Howard et al. (1987) which has been used in similar studies (Osei-Kyei and Chan, 2015; Yi and Wang, 2013; Loveland, Buboltz et al., 2006). From the formula, the contribution of an author to a multi-authored paper decreases from the first author to the last author (American Psychological Association, 2002). The formula is given below:

$$
\frac{1.5^{n-i}}{\sum_{i=1}^{n} 1.5^{i-1}}
$$

Where $n$ denotes the number of authors and $i$ denote the order of each author 


\section{RESULTS AND DISCUSSION}

\section{Annual publication on design for disassembly}

The initial search results revealed over 212 articles related to DfD principles, however sixteen were relevant for the study and considered for further analysis. Theses sixteen articles were retrieved from after filtering were from Proceedings of the CIB Task Group, Procedia Engineering, American Journal of Tourism Management, Environmental Design Guide, Proceedings of Association of Researchers in Construction Management, Resources, Conservation \& Recycling, Waste Management, Building Research \& Information, proceeding of the 2005 Greenbuild Conference and Building \& Environment. Except for Proceeding of CIM Task Group with four publications, each journal or proceeding has one publication each. Figure 1 shows the annual publications and it is worth noting that, years without publications were excluded from the figure. From figure 1, the total number of publications on DfD principles is sixteen and shows an increasing trend from 2000 until 2005 where it decreases and rises again at 2015.

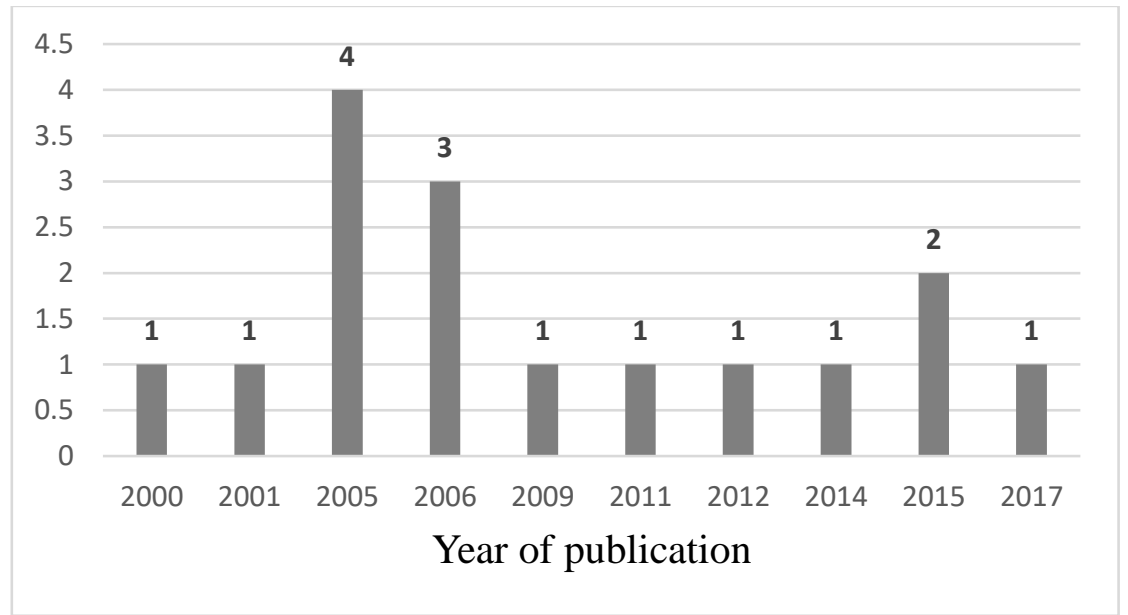

Figure 1. Yearly publications on DfD principles

\section{Authors' origin, country and contribution to DfD}

Howard et al. (1987)'s formula was used in scoring each author in order to determine the most active contributors. The score for each country is accumulated from either a paper with authors from the same country or accumulated from papers with authors of different origin based on the score matrix grounded. In this study, 0.03 goes to Nigeria while 0.97 is awarded to the United Kingdom. A similar approach was used for a multi authored paper. In this away the contribution of each country and author are reported in table 1 and Table 2 below. As presented in Table 1, Australia, United Kingdom and United States of America contributed the most to DfD principles with scores of 5, 4.97 and 3 respectively. In Australia, 2 researchers from different institutions have contributed to 5 publications while in the United Kingdom, 16 researchers from 5 different research centres have contributed to 5 papers. Likewise, in Canada, 2 researchers from two researcher centres have published 2 papers while 7 researchers from 5 researcher centres have published 3 papers in the United States of America. The results of the table indicated how widespread DfD has been among both developed countries and limited developing countries. This 
may be attributed to the fact that these developed countries have huge levels of construction waste and therefore the management of waste being a major priority (Esin and Cosgun, 2007). The low contribution of the other countries may be a results of the few papers originating from these countries probably because the concept of DfD is yet to be fully explored there. This may also be a resultant of the limitation of the sampling procedure.

Table 1. Country of origin for DfD

\begin{tabular}{lcccc}
\hline Country & Research Centres & Num. of Researchers & Num. of Papers & Score \\
\hline Australia & 2 & 2 & 5 & 5 \\
United Kingdom & 5 & 16 & 5 & 4.97 \\
United States of & 5 & 7 & 3 & 3 \\
America & 2 & 2 & 2 & 2 \\
Canada & 2 & 3 & 2 & 1.03 \\
Nigeria & 2 & 4 & 1 & 1 \\
Norway & & & & \\
\hline
\end{tabular}

\section{Authors with the most Dfd Studies}

The most active contributors to DfD principles from 2000 to 2018 are presented in Table 2. The researcher limited the cut-off point to authors with at least 1 score point. As indicated in the table, 3 researchers have at least one score point with one or more papers. Among the 3 shortlisted authors, Crowther P. from the Queensland University of Technology in Australia had four points and 4 sole authored papers. Likewise, Graham P. of the Centre from Sustainable Built Environment, UNSW has 1 score point and 1 sole authored paper. Although the UK and USA ranked second and third respectively on the university ranking, no author from these two countries scored one or more points. Their individual scores being low can be attributed to the high number of authors to a single paper.

Table 2: Authors contribution to DfD principles

\begin{tabular}{lcccc}
\hline Author & Paper & Affiliation & Country & Score Point \\
\hline Crowther, P & 4 & $\begin{array}{c}\text { Queensland University of } \\
\text { Technology, Australia. }\end{array}$ & Australia & 4 \\
\hline Graham, P. & 1 & $\begin{array}{c}\text { Centre for a Sustainable } \\
\text { Built Environment, UNSW }\end{array}$ & Australia & 1 \\
\hline Gorgolewski, M. & 1 & Ryerson University & Canada & 1 \\
\hline
\end{tabular}

This section reports findings on the principles for design for disassembly identified in literature. Table 3 provides a list of the principles identified. This paper discusses top three principles.

\section{Documentation of materials and methods}

The nature of construction projects demands multiple material combinations and processes as well as changes from the commencement to the end of a project. These may come in the form design alterations to the original drawings called variations. Also materials other than specified may be incorporated for quality improvement and cost reduction. The results of these additions and subtractions to working drawings are variations in drawings and the built structure at the end of a 
project. Typically, a contractor furnishes the client or consultant with as-built drawing upon successful completion of the project. These drawing show as on ground the geometry and position of building components and therefore correct positioning without errors is emphasized (Kazaz et al., 2017). Although tedious to produce, detailed knowledge on all embedded materials and processes would save time and other resources spent during disassembly operations (Smith et al., 1993). Lately Building Information Modelling lends its benefits to such ends. Through continuous updates of a single model by different parties, detailed documentation of design, materials and processes can be easily generated at the end of a project.

\section{Standardization of components}

Striving for better grade and homogenous construction elements and process creates more opportunities for reuse and consequently waste reduction. Many opportunities exist for standardization. On a basic level, sandcrete blocks and lumber are typical instances of standardization. More recently modular panels have facilitated extensively mass offsite production and assembly in the housing industry (Xie et al., 2016). One important factor is the property of a single component to be used in many ways. An example is a wall panel member designed to be fit for both $90^{\circ}$ and $180^{\circ}$ angle joints. With an average building's lifespan extending four decades before demolition or deconstruction, the likelihood of predicting particular purposes to which elements will be reused for is very low. However, standardisation and designing with more tolerance allows more opportunities for reuse in future construction. A steel beam mighty not be any suitable for its previous function but may serve more accurately as a column depending on how stringent it was standardised. This extend across roof members, covering, column, and floor member and so on.

\section{Use mechanical joints instead of chemical}

Design for deconstruction is most effective when it allows for maximum disassembly with little or no waste production and environmental pollution. The use of mechanical instead of chemical joints is promoted to this end. Instead of traditional concreting, mortar joints, and timber panels glued to floors, designers for disassembly are entreated to adopt strategies such as mechanical locking system applied currently in areas like floor and wall panels. Some include vertical and horizontal tongue and groove systems displaceable and resilient enough to withstand several reuses. Studies like Pervan (2014) have investigated the possibilities of extinguishing glued joints in floor boarding systems. Steel plates and aluminium frames have been reported to hold perforated brick together quite well instead of mortar joints (Nordby et al., 2009).

\section{CONCLUSION}

This paper in promoting design for disassembly in the construction industry has reported on various principles of DfD identified in literature over a period of 18 years. Yearly publications, the contribution of authors and their background were also identified. The principles identified from literature provides a useful catalogue for other researchers to further investigate current state of design for disassembly. This paper provides insight in incorporating such principles into design at early stages of the construction process and also for developing guides for DfD in future works 


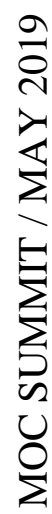

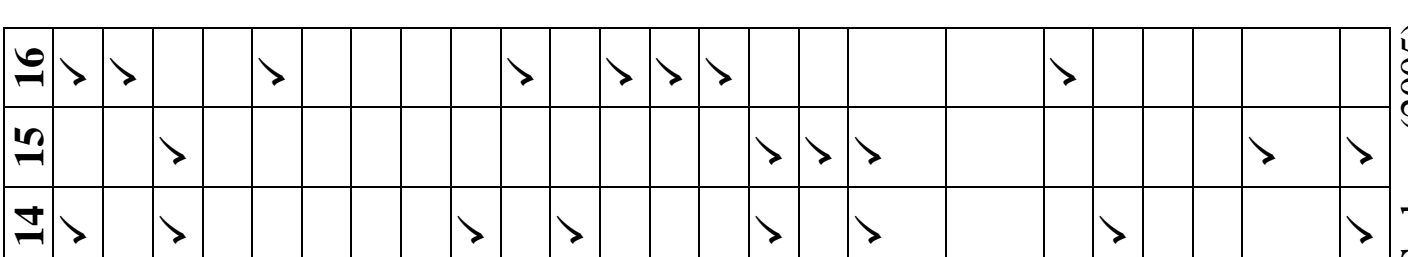

$\ddot{\hat{n}}$

ปู

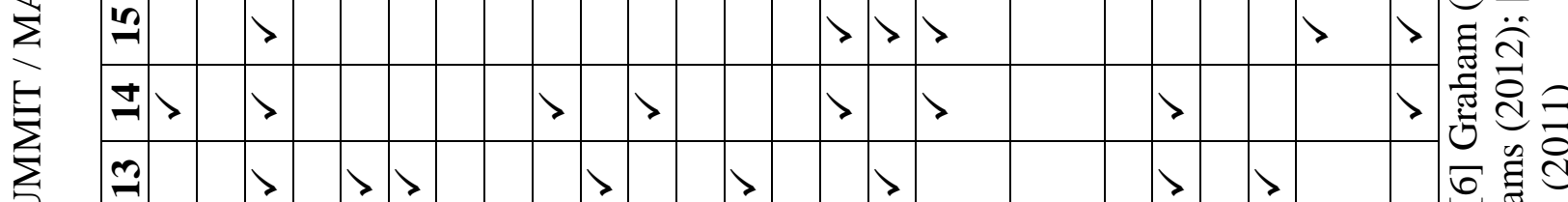

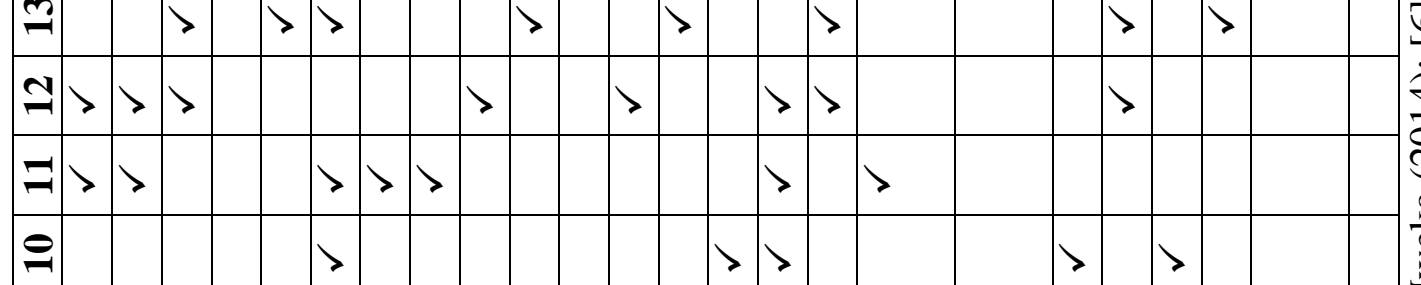

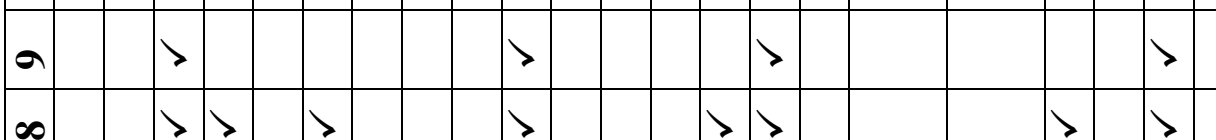

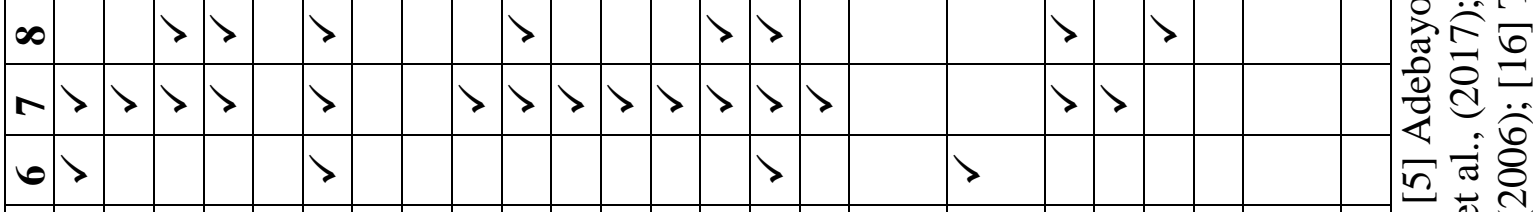

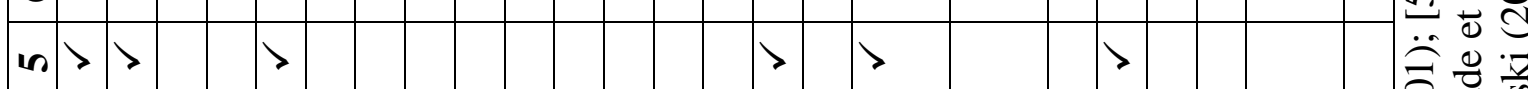

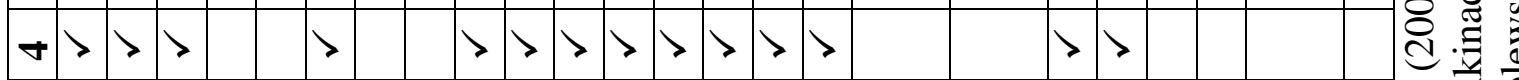

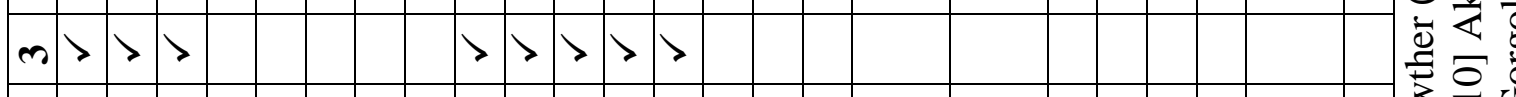

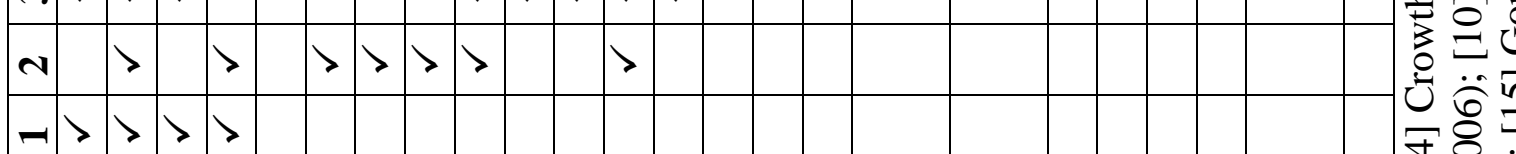

岂苍号

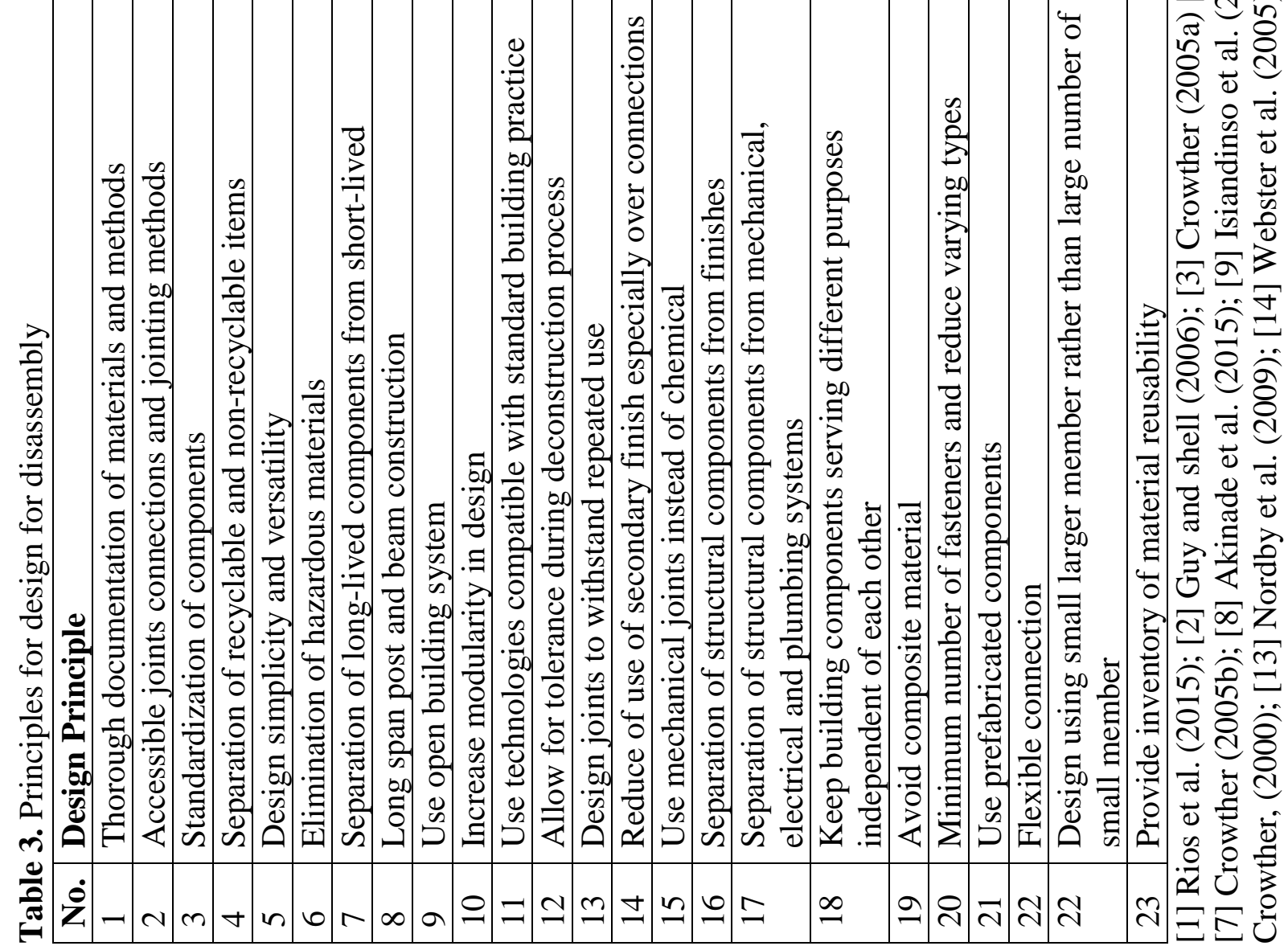


MOC SUMMIT / MAY 2019

\section{REFERENCES}

Adebayo, A. K., \& Iweka, A. C. (2014). Optimizing the sustainability of tourism infrastructure in Nigeria through design for deconstruction framework. American Journal of Tourism Management, 3(1A), 13-19.

Akinade, O. O., Oyedele, L. O., Ajayi, S. O., Bilal, M., Alaka, H. A., Owolabi, H. A., ... \& Kadiri, K. O. (2017). Design for Deconstruction (DfD): Critical success factors for diverting endof-life waste from landfills. Waste management, 60, 3-13.

Akinade, O. O., Oyedele, L. O., Bilal, M., Ajayi, S. O., Owolabi, H. A., Alaka, H. A., \& Bello, S. A. (2015). Waste minimisation through deconstruction: A BIM based Deconstructability Assessment Score (BIM-DAS). Resources, Conservation and Recycling, 105, 167-176.

American Psychological Association. (2002). Ethical principles of psychologists and code of conduct. American psychologist, 57(12), 1060-1073.

Couto, J., \& Couto, A. (2010). Analysis of barriers and the potential for exploration of deconstruction techniques in Portuguese construction sites. Sustainability, 2(2), 428-442.

Crowther P (2000) Developing guidelines for designing for deconstruction. Deconstruction - Closing the Loop. Watford, UK: BRE.

Crowther P. (2005). Design for Disassembly- Themes and Principles. Environmental Design Guide, 1-7. Available at: http://eprints.qut.edu.au/2888/1/Crowther-. RAIA-2005.PDF.

Crowther, P. (1999). Designing for Disassembly to Extend Service Life and Increase Sustainability. Paper presented at the 8th International Conference on Durability of Building Materials and Components, Vancouver, Canada.

Crowther, P. (2001). Developing an Inclusive Model for Design for Deconstruction, Deconstruction and Materials Reuse: Technology. Economic, and Policy, CIB Publications, Wellington.

Crowther, P. (2002). Design for Buildability and the Deconstruction Consequences. Proceeding of the CIB. Task Group 39, 272, 7-15.

Crowther, P. (2005). The state of building deconstruction in Australia. Deconstruction and Materials Reuse-an International Overview, Gainesville: CIB and the University of Florida, 300, 23-54.

Debacker W., Henrotay C., Paduart A., Elsen. S., W.P. De Wilde, Hendrickx H., 2007, Fourdimensional design: from strategies to cases - generation of fractal grammar for reusing building elements, International Journal of. Ecodynamics, 2, No 4, 258-277.

Esin, T., \& Cosgun, N. (2007). A study conducted to reduce construction waste generation in Turkey. Building and Environment, 42(4), 1667-1674.

Gorgolewski, M. (2006). The implications of reuse and recycling for the design of steel buildings. Canadian Journal of Civil Engineering, 33(4), 489-496.

Graham, P. (2005). Design for adaptability — an introduction to the principles and basic strategies. Environment Design Guide, 1-9.

Guy, B. \& Shell, S. (2006). Design for deconstruction and materials reuse. Proceedings of the CIB Task Group, 39(4), 189-209.

Hobbs, G., \& Adams, K. (2012). Assessing levels of Deconstruction and Recyclability. CIB W115 Green Design Conference. Publication.

Isiadinso, C, Anumba, C.J, El-Rimawi, J, and Bhamra, T (2006) Design for deconstruction lessons from the manufacturing industry. In: Boyd, D (Ed) Procs 22nd Annual ARCOM Conference,4-6September 2006, Birmingham, UK, Association of Researchers in Construction Management, 937-946. 
Isiadinso, C., Anumba, C. J., El Rimawi, J., Bhamra, T. (2006) Design for Deconstruction: lessons from the manufacturing industry. In Boyd, D (ed) Proceedings of Association of Researchers in Construction Management (ARCOM), Birmingham, UK, pp.937-946.

Kazaz, A., Ac1kara, T., Ulubeyli, S., \& Koyun, H. (2017). Detection of Architectural Drawings Errors in 3 Dimension. Procedia Engineering, 196, 1018-1025.

Khalili, A., \& Chua, D. K. H. (2011). Framework for an IFC-based tool for implementing design for deconstruction (DfD). In Computing in Civil Engineering (2011) (pp. 619-626).

Loveland, J. M., Buboltz, W. C., Schwartz, J., \& Gibson, G. (2006). Content analysis of CDQ from 1994-2003: Implications and trends for practitioners and researchers from a decade of research. Career Development Quarterly, 54(3), 256-264.

Nordby, A. S., Berge, B., Hakonsen, F., \& Hestnes, A. G. (2009). Criteria for salvageability: the reuse of bricks. Building Research \& Information, 37(1), 55-67.

Pervan, D. (2014). U.S. Patent No. 8,733,410. Washington, DC: U.S. Patent and Trademark Office.

Rios, F. C., Chong, W. K., \& Grau, D. (2015). Design for disassembly and deconstructionchallenges and opportunities. Procedia engineering, 118, 1296-1304.

Smith, G. R., \& Raynar, K. (1993). Application on Digital Images and Processing for As-Built Construction Drawings. In Digital Image Processing: Techniques and Applications in Civil Engineering American Society of Civil Engineers National Science Foundation Engineering Foundation.

Tingley, D. D., \& Davison, B. (2011). Design for deconstruction and material reuse. Proceedings of the institution of civil engineers-energy, 164(4), 195-204.

Webster, M. D., \& Costello, D. T. (2005). Designing structural systems for deconstruction: how to extend a new building's useful life and prevent it from going to waste when the end finally comes. In Proceedings of the 2005 Greenbuild conference, Atlanta, USA.

Xie, Z., Hall, J., McCarthy, I. P., Skitmore, M., \& Shen, L. (2016). Standardization efforts: The relationship between knowledge dimensions, search processes and innovation outcomes. Technovation, 48, 69-78. 